\title{
Rencontres du vers et de la prose: conscience poétique et mise en texte, sous la dir. de Catherine CROIZY-NAQUET et Michelle SZKILNIK
}

\author{
Maria Colombo Timelli
}

\section{OpenEdition}

\section{Journals}

\section{Édition électronique}

URL : http://journals.openedition.org/studifrancesi/14849

DOI : $10.4000 /$ studifrancesi. 14849

ISSN : 2427-5856

\section{Éditeur}

Rosenberg \& Sellier

\section{Édition imprimée}

Date de publication : 1 décembre 2018

Pagination : 470-471

ISSN : 0039-2944

\section{Référence électronique}

Maria Colombo Timelli, «Rencontres du vers et de la prose: conscience poétique et mise en texte, sous la dir. de Catherine croizY-naquet et Michelle szKILnIK », Studi Francesi [En ligne], 186 (LXII | III) | 2018, mis en ligne le 01 janvier 2019, consulté le 06 janvier 2021. URL : http://journals.openedition.org/ studifrancesi/14849; DOI : https://doi.org/10.4000/studifrancesi.14849

Ce document a été généré automatiquement le 6 janvier 2021.

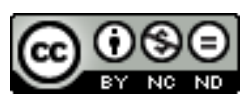

Studi Francesi è distribuita con Licenza Creative Commons Attribuzione - Non commerciale - Non opere derivate 4.0 Internazionale. 


\title{
Rencontres du vers et de la prose: conscience poétique et mise en texte, sous la dir. de Catherine CROIZY- NAQUET et Michelle SZKILNIK
}

\author{
Maria Colombo Timelli
}

\section{RÉFÉRENCE}

Rencontres du vers et de la prose: conscience poétique et mise en texte, sous la dir. de Catherine CROIZY-NAQUET et Michelle SZKILNIK, Paris, Presses Sorbonne Nouvelle, 2017.

1 Ce volume réunit les Actes d'une rencontre organisée à l'Université de la Sorbonne Nouvelle en mars 2015; il suit et complète le recueil Rencontres du vers et de la prose: conscience théorique et mise en page (colloque de décembre 2013, Actes publiés en 2016), dont on a rendu compte dans «SF» 182, pp. 335-336. Dans la Préface, les deux directrices justifient le sujet et l'encadrent au sein de la pensée théorique actuelle sur les deux formes; surtout, elles expliquent le souhait, tout à fait légitime, d'élargir la réflexion à d'autres aires linguistiques et à une diachronie plus ample que le Moyen Âge au sens strict (pp. 11-25).

Ouvrant la section consacrée à la production française médiévale, Maria CARERI propose quelques remarques sur le rapport éventuel entre (types de) fautes involontaires commises par les copistes et forme du texte, en vers ou en prose. Une cinquantaine d'exemples tirés d'un corpus de textes en ancien français permettent de dresser une typologie et de reconnaittre les conditions et les causes qui ont produit des erreurs ( $A$ chacun ses erreurs... Versi e prosa: problemi di copia, pp. 81-92).

Joëlle Ducos examine le rôle de la forme-vers dans ce «genre» si difficile à cerner et à définir qu'est l'écriture des savoirs au Moyen Âge. Parmi les textes évoqués, on retiendra la réfection en vers par Priorat de Besançon du De re militari traduit par Jean 
de Meun, le Livre du pèlerin de vie humaine de Guillaume de Digulleville, Renard le Contrefait, Fauvel, le Chemin de Longue estude de Christine de Pizan. Elle peut ainsi reconnaître la relation profonde qui s'instaure au XIV siècle entre vers, science et écriture allégorique, et qui différencie cette production de la poésie scientifique du $\mathrm{XVI}^{\mathrm{e}}$ (Écrire en vers après la prose: vers une poésie scientifique? pp. 93-110)

Dans l'ensemble de son œuvre (Mémoires, Livre de Forme de Plait, Quatre âges de l'Homme), Philippe de Novare établit un système de formes tripartite, comprenant «rime», «chanson», «conte»; Florence TANNIOU les définit comme des formes complémentaires: la «rime» représente une forme versifiée excluant le chant et l'accompagnement musical qu'implique la «chanson», alors qu'en l'absence du terme "prose», «conte» renvoie au «mode énonciatif d'un contenu narratif ou didactique» (p. 119). D'autre part, elle relève aussi une présence variée des vers dans les trois traités: anecdotique dans le Livre, plus importante dans les Quatre âges, encore davantage dans les Mémoires, qui seuls accueillent des «chansons» (Rimes, chansons, conte. Vers et prose dans l'œuvre de Philippe de Novare, pp. 111-125).

5 Jelle Koopmans s'interroge sur la pertinence de l'opposition moderne vers/prose en se concentrant en particulier sur Aucassin et Nicolette, texte partiellement théâtral dont l'unique manuscrit contient tant des «didascalies» qu'une notation musicale. Le Dit de l'Herberie de Rutebeuf, qui alterne aussi vers et prose, doit être également considéré comme un des premiers monologues dramatiques en français ( $O$ On écrit des vers - de la prose», mais que dit-on sur la scène?, pp. 127-139).

6 Se basant sur un double corpus, français et allemand, Klaus RIDDER et Darwin SMITH vérifient la présence éventuelle de sections en prose, quelques caractéristiques matérielles des manuscrits "de théâtre», la performance des parties chantées, l'incidence de la gestuelle, et enfin les «rôles» du Prêcheur et du Fou ainsi que leurs exécutions sur scène. Dans l'ensemble, ils soulignent la grande distance existant «entre ce qui est écrit et ce qui est joué, entre les appuis d'une réplique versifiée sur le papier, et ce qui sera dit et mis en évidence en performance» (Aux confins du vers et de la prose: Prêcheurs et Fous dans les jeux allemands et français du Moyen Âge, pp. 141-164, cit. p. 164). 